\title{
Feeding Behavior Comparison of Soybean Aphid (Hemiptera: Aphididae) Biotypes on Different Soybean Genotypes
}

\author{
PREDEESH CHANDRAN,${ }^{1}$ JOHN C. REESE, ${ }^{1,2}$ SHAH ALAM KHAN,${ }^{1}$ DECHUN WANG, ${ }^{3}$ \\ WILLIAM SCHAPAUGH ${ }^{4}{ }^{\text {AND LESLIE R. CAMPBELL }}{ }^{1}$
}

\begin{abstract}
J. Econ. Entomol. 106(5): 2234-2240 (2013); DOI: http://dx.doi.org/10.1603/EC13126
ABSTRACT Soybean aphids have become a serious pest of soybean, Glycine max L. (Merrill), since they were first detected in North America in 2000. Three soybean aphid biotypes have been documented in the United States in the last $10 \mathrm{yr}$, but few studies have been done on their feeding behavior in the United States The Electrical Penetration Graph is a convenient and successful tool to study the feeding behavior of piercing and sucking insects. This is the first attempt to study the feeding behavior differences between biotype 1 and biotype 2 on soybean genotypes using the Electrical Penetration Graph technique, and includes both resistant and susceptible soybean genotypes from Kansas and Michigan. The experiments were run for $9 \mathrm{~h}$ each for each genotype with a total of eight channels at a time. Results indicated that aphids feeding on susceptible genotypes had a significantly greater duration of sieve element phase than when feeding on resistant genotypes. Furthermore, the time taken to reach the first sieve element phase in resistant genotypes was significantly greater than in susceptible genotypes. Most of the aphids reached sieve element phase $(>90 \%)$ in susceptible genotypes, but only a few $(<30 \%)$ reached sieve element phase in resistant genotypes during the 9-h recording period; however, we found no differences in any other probing phases between resistant and susceptible genotypes except the number of potential drops in biotype 2 . Thus, the resistance was largely associated with phloem tissues. Therefore, some biochemical, physical, or morphological factors could affect stylet penetration of aphids.
\end{abstract}

KEY WORDS EPG, aphid biotype, soybean genotype, feeding behavior

The soybean aphid (Aphis glycines Matsumura), which originated in eastern Asia, is an invasive pest in North America from the center of the United States to the southern provinces of Canada (Ragsdale et al. 2004). It is a major pest of soybean, Glycine $\max (\mathrm{L}$.) Merrill, and may cause a yield loss of $>50 \%$ in the United States and in Chinese provinces (Wang et al. 1996, Ostlie 2002). Following its first detection in the United States in 2000, this aphid rapidly spread throughout U.S. soybean-growing areas; $\approx 80 \%$ of the soybean fields were infested by 2004 (Venette and Ragsdale 2004). Soybean yield loss is caused mainly by direct feeding on plant tissues, especially the vascular tissues, and indirectly by the transmission of viruses during feeding and reduction in seed and pod quality (Ragsdale et al. 2007). Transmission of viruses such as soybean aphid mosaic virus and soybean dwarf virus is a serious threat associated with soybean aphid infestation (Clark and Perry 2002). Up to US $\$ 5$ billion can be lost in soybean production annually because of

\footnotetext{
${ }^{1}$ Department of Entomology, Kansas State University, 123 West Waters Hall, Manhattan, KS 66506.

${ }^{2}$ Corresponding author, e-mail: jreese@ksu.edu.

${ }^{3}$ Department of Crop \& Soil sciences, Michigan State University, MI 48824

${ }^{4}$ Department of Agronomy, Kansas State University, Manhattan, KS 66506 .
}

insecticide application, which in turn depends on the size of the soybean aphid outbreak and the price flexibility of soybean supply (Kim et al. 2008a).

The first research triumphs in resistant varieties of soybean were the discovery of Ragl and Rag, two single dominant genes for controlling soybean aphid damage in Dowling and Jackson genotypes (Hill et al. 2006a,b). Until recently, multiple soybean aphid biotypes were not identified in North America. Two biotypes were first distinguished from Illinois and Ohio soybean fields and were reported as the Illinois and Ohio biotypes, respectively, based on the tests done using the Ragl gene in the biotypes (Kim et al. 2008b). In 2009, these two biotypes were renamed biotype 1 and biotype 2 , respectively (Hill et al. 2009). Later in 2007, a new biotype, biotype 3, was identified from aphids collected from Springfield Fen, IN; this biotype shows resistance to plants with Rag 2 (Hill et al. 2010).

Aphids are piercing and sucking insects that cause injury through direct feeding with their needle-like mouth parts (stylets) in plant tissues, especially removal of phloem sap from sieve elements in the vascular tissue (Crompton and Ode 2010). The Electronic Monitoring System, first described by McLean and Kinsey (1964) using alternate current (AC), has been used to record the feeding behavior of aphids and observe the resistance mechanism of plants (Re- 
ese et al. 2000). This technique also helps find intracellular and intercellular locations of the stylets without damaging living cells in the plant tissue (Tjallingii 1988). The technique has been reviewed extensively in recent years (Ellsbury et al. 1994, Walker and Backus 2000).

Han and Yan (1995) first reported the use of the electrical penetration graph (EPG) techniques for monitoring feeding behavior of soybean aphids. They found that phloem ingestion from Gossypium hirsutum (L.), Cucumis sativa (L.), and Luffa cylindrical (L.) (nonhost plants) was less than that from the host plant, Glycine max. Later, Diaz-Montano et al. (2007) carried out EPG studies on feeding behavior of the soybean aphid on resistant and susceptible soybean genotypes. Their results showed that the duration of the sieve element phase was long in susceptible genotypes and very short in resistant genotypes. Crompton and Ode (2010) conducted EPG experiments with a resistant soybean genotype, 'Dowling,' and a susceptible soybean genotype, 'Glenwood,' and found that antibiotic resistance resides in the phloem tissue of the resistant genotype but not in any other plant tissues.

The objective of our study was to compare the feeding behavior between the two of soybean aphid biotypes using EPG technique on different resistant and susceptible soybean genotypes. In the current study, we used four soybean genotypes (E06902, E07906-2, K1639, and KS4202) and two soybean aphid biotypes (biotype 1 and biotype 2). Only a few EPG studies have been conducted on soybean with soybean aphid; this study is the first in a series including two biotypes of soybean aphid recorded on different resistant and susceptible genotypes. This is also the first EPG study with biotype 2 in United States since it was first reported in 2006 (Kim et al. 2008b).

\section{Materials and Methods}

Aphid Cultures and Soybean Genotypes. Soybean aphid biotype 1 was collected from fields in Nebraska in spring and July of 2008, and biotype 2 was collected from fields of Ohio and kindly provided by Brian W. Diers, Department of Crop Sciences, University of Illinois, Urbana, IL. Voucher specimens 180 and 218 have been filed at the Kansas State University Museum of Entomological and Prairie Arthropod Research for biotype 1 and biotype 2 , respectively. Aphid colonies were maintained on susceptible soybean genotype KS4202 in different locations for each biotype to avoid contamination. The biotype 1 colony was maintained in a cage with ventilation under pesticide-free greenhouse conditions at $20-30^{\circ} \mathrm{C}, 23-40 \%$ relative humidity $(\mathrm{RH})$, and supplemental high-pressure sodium vapor lamps set for a photoperiod of 14:10 (L:D) h. The biotype 2 colony was located in the laboratory inside a growth chamber (Percival Scientific, Inc., Perry, IA) under environmental conditions similar to the greenhouse. During the experiments, biotype 1 was transported to the laboratory in tightly closed petri dishes to avoid contamination from the environment and biotype 2 aphids. However, experiments with the two aphid biotypes were conducted separately as an extra measure to avoid mixing up of biotypes during collecting, wiring, and recording (some aphids may accidently detach from the wire at the time of probing).

Soybean genotypes used in these experiments included E06902, E07906-2, K1639, and KS4202. Genotypes E06902 and E07906-2 have been shown to be resistant to biotype 2 while K1639 is resistant only to biotype 1 (P. C., unpublished data). Thus for biotype 1, three resistant plants (E06902, E07906-2, and K1639) and one susceptible (KS4202) plant were used in each experiment. But for biotype 2, two resistant (E06902 and E07906-2) and two susceptible (K1639 and KS4202) plants were used. Soybean plants were grown individually in plastic cone-tainers $(3.8 \mathrm{~cm}$ in diameter and $21.0 \mathrm{~cm}$ in depth) (Ray Leach Conetainer, Hummert International, Earth City, MO) filled with steam-sterilized potting mix (Premier Promix, Rivièredu-Loup, Québec, Canada) and were kept under sodium vapor lamps in laboratory conditions. Plants used for the experiments were in V1 stage or $9 \mathrm{~d}$ after planting (Diaz-Montano et al. 2007).

EPG Recording and Experimental Design. Experiments were conducted at room temperature (22$26^{\circ} \mathrm{C}$, $35-45 \% \mathrm{RH}$, and with fluorescent ceilingmounted lamps for illumination. At the beginning of the experiments, adult apterous aphids were collected from the respective aphid colonies using a moist camel's-hair brush (number 0 ) to avoid bodily damage, and were kept starved in a petri dish for $1 \mathrm{~h}$ (DiazMontano et al. 2007). A thin gold wire (10-12 $\mu \mathrm{m}$ in diameter and 2-3 cm in length) (Johnson Matthey, Materials Tech, Royston, England) was attached to the dorsum of aphids using high-purity conductive silver paint (SPI Supplies, West Chester, PA). The opposite end of the gold wire was attached to a copper wire, $0.2 \mathrm{~mm}$ in diameter and $1-2 \mathrm{~cm}$ in length, and this copper wire was soldered to a copper nail ( 1.6 by 19.0 $\mathrm{mm})$. This served as an insect electrode. The plant electrode consisted of a copper wire $(2 \mathrm{~mm}$ in thickness and $10 \mathrm{~cm}$ in length) inserted into the soil of a potted plant (Tjallingii 1988).

The two electrodes (insect and plant) were connected to a Giga-8 DC EPG monitor with $10^{9} \Omega$ input resistance and 50-100 $\times$ amplifications (Wageningen Agricultural University, Wageningen, The Netherlands). The insects and plants were kept inside a Faraday cage to avoid electrical noise during the recording of EPG. EPGs were recorded from aphids feeding on the upper side of the fully developed unifoliate leaf. The voltage source was adjusted so that the output signal voltage was between +5 and $-5 \mathrm{~V}$, and the signal voltage was positive when the stylet tips were in an intercellular position and was negative during intracellular punctures (Tjallingii 2006). Eight channels, each with one soybean plant and one insect electrode, were used to record EPG output. Each repetition of an experiment included eight plants, two for each of the four genotypes. EPG output was recorded continuously for $9 \mathrm{~h}$ for each of 15 replications from each genotype. Output was digitized and annotated using 
Table 1. Comparison of EPG variables (mean \pm SE) for soybean biotype 1 feeding on resistant and susceptible soybean genotypes for a 9 -h (540-min) time period

\begin{tabular}{|c|c|c|c|c|c|c|c|c|}
\hline \multirow{2}{*}{ No. } & \multirow{2}{*}{ Feeding behavior variable } & \multicolumn{4}{|c|}{ Genotype $^{a}$} & \multirow{2}{*}{$\chi^{2}$} & \multirow{2}{*}{ df } & \multirow{2}{*}{$P$} \\
\hline & & $\mathrm{E} 06902(\mathrm{R})$ & E07906-2 (R) & K1639 (R) & KS4202 (S) & & & \\
\hline 1 & $\begin{array}{l}\text { Time from beginning of recording to first probe } \\
\text { (FP) }\end{array}$ & $14.6 \pm 1.4$ & $12.4 \pm 1.4$ & $17.6 \pm 1.4$ & $9.4 \pm 1.4$ & 1.32 & 3 & 0.2798 \\
\hline 2 & $\begin{array}{l}\text { Time from beginning of recording to first xylem } \\
\text { phase (f-XP) }\end{array}$ & $144.3 \pm 28.8$ & $199.0 \pm 28.8$ & $160.5 \pm 28.8$ & $127.2 \pm 28.8$ & 1.14 & 3 & 0.3444 \\
\hline 3 & $\begin{array}{l}\text { Time from beginning of recording to first sieve } \\
\text { element phase (f-SEP) }\end{array}$ & $492.1 \pm 19.9 \mathrm{a}$ & $509.9 \pm 19.9 \mathrm{a}$ & $468.6 \pm 19.9 \mathrm{a}$ & $135.6 \pm 19.9 b$ & 63.92 & 3 & $<0.0001$ \\
\hline 4 & $\begin{array}{l}\text { Time from beginning of probe to sieve element } \\
\text { phase }\end{array}$ & $468.3 \pm 16.5 \mathrm{a}$ & $487.6 \pm 16.5 \mathrm{a}$ & $428.2 \pm 16.5 \mathrm{a}$ & $112 \pm 16.5 b$ & 56.92 & 3 & $<0.0001$ \\
\hline 5 & No. of pathway phases (n-PP) & $15.9 \pm 1.9$ & $20.0 \pm 1.9$ & $17.3 \pm 1.9$ & $18.4 \pm 1.9$ & 0.84 & 3 & 0.4793 \\
\hline 6 & No. of xylem phases (n-XP) & $2.0 \pm 0.3$ & $2.5 \pm 0.3$ & $1.6 \pm 0.3$ & $1.7 \pm 0.3$ & 2.80 & 3 & 0.0507 \\
\hline 7 & No. of sieve element phases (n-SEP) & $0.4 \pm 0.4 \mathrm{~b}$ & $0.3 \pm 0.4 \mathrm{~b}$ & $0.2 \pm 0.4 \mathrm{~b}$ & $2.00 \pm 0.4 \mathrm{a}$ & 11.76 & 3 & $<0.0001$ \\
\hline 8 & Duration per insect of pathway phase (s-PP) & $256.5 \pm 18.5$ & $249.5 \pm 18.5$ & $302.6 \pm 18.5$ & $267.3 \pm 18.5$ & 0.05 & 3 & 0.9868 \\
\hline 9 & Duration per insect of xylem phase (s-XP) & $72.5 \pm 12.5$ & $70.5 \pm 12.5$ & $80.2 \pm 12.5$ & $85.2 \pm 12.5$ & 0.13 & 3 & 0.8237 \\
\hline 10 & Duration per insect of nonprobing (s-NP) & $191.3 \pm 20.3$ & $181.4 \pm 20.3$ & $140.3 \pm 20.3$ & $160.2 \pm 20.3$ & 0.19 & 3 & 0.9009 \\
\hline 11 & $\begin{array}{l}\% \text { time aphid spent in sieve element phase after } \\
\text { the first probe to sieve elements (\% SEP) }\end{array}$ & $2.8 \pm 0.2 \mathrm{~b}$ & $2.0 \pm 0.2 \mathrm{~b}$ & $2.2 \pm 0.2 b$ & $13.6 \pm 0.2 \mathrm{a}$ & 39.30 & 3 & $<0.0001$ \\
\hline 12 & $\begin{array}{l}\text { No. of aphids that reached the sieve element } \\
\text { phase }(n=15)^{c}\end{array}$ & 3 & 2 & 5 & 15 & & & \\
\hline
\end{tabular}

\footnotetext{
${ }^{a}$ Values followed by different letters are significantly different within a row $(P<0.05$; Tukey's test).

${ }^{b}$ Time is calculated in minutes.

${ }^{c}$ All replicates are included in final analyses.
}

PROBE 3.0 (Windows) software (Wageningen Agricultural University, Wageningen, The Netherlands) (Tjallingii 1988) at a rate of 100 samples per s.

Different Feeding Variables and Statistical Analyses. Response variables calculated and statistically compared in this experiment were almost the same as those recorded earlier by Diaz-Montano et al. (2007) on resistant and susceptible soybean genotypes. Variables are similar to those of Sarria et al. (2009). The following variables were expressed as means per event for each type described: 1) time from beginning of recording to first pathway phase or first probe (FP); 2) time from the beginning of recording to first xylem phase (f-XP); 3 ) time from the beginning of recording to first sieve element phase (f-SEP); 4) time from the beginning of probe to first sieve element phase; 5) number of pathway phases (n-PP);6) number of xylem phases (n-XP); 7) number of sieve element phases (n-SEP); 8) number of potential drops (n-PD). In addition, the following variables were calculated by summing no's or durations of all events of each type for each insect, then averaging across insects to achieve the mean per insect: 9) duration of pathway phase $(\mathrm{s}-\mathrm{PP}) ; 10)$ duration of xylem phase $(\mathrm{s}-\mathrm{XP}) ; 11) \mathrm{du}-$ ration of nonprobing (resting phase) (s-NP); and 12) duration of sieve element phase (s-SEP). Finally, 13) the mean percentage of time that an (average) aphid spent in sieve elements since first probing phloem tissues (percentage SEP); and 14) the mean number of aphids that reached the sieve element during the 9 -h recording period. One of the main objectives of this study was to compare the time aphids spent in the phloem phase and nonphloem phases (pathway phase and xylem phase) in resistant and susceptible genotypes. Consequently, both E1 and E2 sieve element waveforms were considered as a single $\mathrm{E}$ waveform in this study (Annan et al. 2000, Diaz-Montano et al.
2007). Furthermore, for those aphids that did not reach the sieve element phase or xylem phase during the entire experiment, the time from beginning of recording to first sieve element phase or first xylem phase was taken as $9 \mathrm{~h}$, that is, the total time of a EPG recording in this study (Prado and Tjallingii 1997, Diaz-Montano et al. 2007).

The feeding behavior variables were analyzed and calculated separately for the two soybean aphid biotypes (biotype 1 and biotype 2). Most of the variables in this study were compared with Tukey's studentized range test $(P<0.05)$ between the four genotypes. In addition, the feeding behavior variable, s-SEP, was not normally distributed and ranged from zero or low duration to long durations. Therefore, the s-SEP data were performed a logarithmic transformation before the Tukey's comparison between the treatments. Finally, transformed data were reconverted to original scale for summarization of the variable. SAS (SAS Institute 2006) was used for all statistical analysis.

\section{Results}

For the first variable (Tables 1 and 2), time from the beginning of recording to the first pathway phase (first probe, FP) did not significantly differ among the four genotypes $(P<0.05)$ for either biotype; for the second variable, time from the beginning of recording to first xylem phase (f-XP) did not significantly differ between the four genotypes $(P<0.05)$ for biotype 1 (Table 1$)$ but biotype 2 took significantly $(P<0.05)$ more time to the first xylem phase on the two resistant genotypes (E06902 and E07906-2) than in the two susceptible genotypes (K1639 and KS4202) (Table 2). For the third variable, time from the beginning of recording to the initiation of first sieve element phase (f-SEP) differed significantly $(P<0.05)$ between sus- 
Table 2. Comparison of EPG variables (mean \pm SE) for soybean aphid biotype 2 feeding on resistant and susceptible soybean genotypes for a 9 -h (540-min) time period

\begin{tabular}{|c|c|c|c|c|c|c|c|c|}
\hline \multirow{2}{*}{ No. } & \multirow{2}{*}{ Feeding behavior variable } & \multicolumn{4}{|c|}{ Genotype $^{a}$} & \multirow{2}{*}{$\chi^{2}$} & \multirow{2}{*}{$\mathrm{df}$} & \multirow{2}{*}{$P$} \\
\hline & & $\mathrm{E} 06902(\mathrm{R})$ & $\mathrm{E} 07906-2(\mathrm{R})$ & K1639 (S) & $\mathrm{KS} 4202(\mathrm{~S})$ & & & \\
\hline 1 & $\begin{array}{l}\text { Time from beginning of recording to first probe } \\
\text { (FP) }\end{array}$ & $17.6 \pm 1.4$ & $7.569 \pm 1.4$ & $6.2 \pm 1.4$ & $10.3 \pm 1.4$ & 0.61 & 3 & 0.6098 \\
\hline 2 & $\begin{array}{l}\text { Time from beginning of recording to first xylem } \\
\text { phase (f-XP) }\end{array}$ & $295.7 \pm 33.8 \mathrm{ab}$ & $235.9 \pm 33.8 \mathrm{a}$ & $112.7 \pm 33.8 b$ & $110.3 \pm 33.8 b$ & 5.96 & 3 & 0.0017 \\
\hline 3 & $\begin{array}{l}\text { Time from beginning of recording to first sieve } \\
\text { element phase (f-SEP })^{b}\end{array}$ & $487.1 \pm 31.2 \mathrm{a}$ & $485.8 \pm 31.2 \mathrm{a}$ & $184.3 \pm 31.2 b$ & $147.1 \pm 31.2 b$ & 28.29 & 3 & $<0.0001$ \\
\hline 4 & $\begin{array}{l}\text { Time from beginning of probe to sieve element } \\
\text { phase }\end{array}$ & $445 \pm 24.6 \mathrm{a}$ & $472.3 \pm 24.6 \mathrm{a}$ & $156.4 \pm 24.6 \mathrm{a}$ & $123.9 \pm 24.6 \mathrm{~b}$ & 19.2 & 3 & $<0.0001$ \\
\hline 5 & No. of pathway phases (n-PP) & $11.5 \pm 1.4 \mathrm{~b}$ & $19.3 \pm 1.4 \mathrm{a}$ & $10.3 \pm 1.4 \mathrm{bc}$ & $6.11 \pm 1.4 \mathrm{c}$ & 15.28 & 3 & $<0.0001$ \\
\hline 6 & No. of xylem phases (n-XP) & $1.6 \pm 0.5$ & $2.1 \pm 0.5$ & $2.5 \pm 0.5$ & $1.8 \pm 0.5$ & 0.64 & 3 & 0.5945 \\
\hline 7 & No. of sieve element phases (n-SEP) & $0.3 \pm 0.4 \mathrm{~b}$ & $0.4 \pm 0.4 \mathrm{~b}$ & $2.4 \pm 0.4 \mathrm{a}$ & $1.9 \pm 0.4 \mathrm{a}$ & 6.90 & 3 & 0.0007 \\
\hline 8 & Duration per insect of pathway phase (s-PP) & $253.3 \pm 21.7$ & $210.8 \pm 21.7$ & $183.5 \pm 21.7$ & $237.7 \pm 21.7$ & 2.00 & 3 & 0.1274 \\
\hline 9 & Duration per insect of xylem phase (s-XP) & $82.1 \pm 16.2$ & $33.3 \pm 16.2$ & $90.3 \pm 16.2$ & $61.4 \pm 16.2$ & 2.46 & 3 & 0.0756 \\
\hline 10 & Duration per insect of nonprobing (s-NP) & $159.2 \pm 20.5$ & $183.6 \pm 20.5$ & $162.4 \pm 20.5$ & $177.9 \pm 20.5$ & 0.33 & 3 & 0.8014 \\
\hline 11 & $\begin{array}{l}\% \text { time aphid spent in sieve element phase after } \\
\text { the first probe to sieve elements (\% SEP) }\end{array}$ & $4.5 \pm 2.3 \mathrm{~b}$ & $5.3 \pm 2.3 b$ & $19.6 \pm 2.3 \mathrm{a}$ & $15.5 \pm 0.3 \mathrm{a}$ & 19.96 & 3 & $<0.0001$ \\
\hline 12 & $\begin{array}{l}\text { No. of aphids that reached the sieve element } \\
\text { phase }(n=15)^{c}\end{array}$ & 5 & 4 & 13 & 15 & & & \\
\hline
\end{tabular}

\footnotetext{
${ }^{a}$ Values followed by different letters are significantly different within a row $(P<0.05$; Tukey's test).

${ }^{b}$ Time is calculated in minutes.

${ }^{c}$ All replicates are included in final analyses.
}

ceptible genotypes and resistant genotypes for both biotypes (Tables 1 and 2). Time to first sieve element phase was significantly shorter $(P<0.05)$ on susceptible genotype (KS4202) for biotype 1 and KS4202 and K1639 for biotype 2. Similarly for the fourth variable, time from beginning of probe to first sieve element phase was significantly greater $(P<0.05)$ on resistant genotypes for both biotypes.

Comparing the mean number of two phases [pathway (n-PP) and xylem (n-XP)] (variables 5 and 6; Tables 1 and 2) in biotype 1, we found no significant difference $(P<0.05)$ in mean numbers for pathway and xylem phases in resistant and susceptible genotypes, but for biotype 2 the pathway phase (n-PP) was significantly greater $(P<0.05)$ for resistant genotypes compared with the susceptible genotypes. However, for the seventh variable, the number of sieve element phases (n-SEP) was significantly greater for the genotypes that were susceptible versus the genotypes that were resistant to their respective aphid biotypes (Tables 1 and 2). The mean number of potential drops (n-PD) did not differ significantly $(P<0.05)$ between susceptible and resistant genotypes for biotype 1 (Fig. 1). However biotype 1 did perform numerically more pd's on the resistant genotypes, E06902 and E07906-2, than on the susceptible genotype (KS4202), or the putatively resistant genotype, K1639 (Fig. 1). For biotype 2 , the mean numbers of potential drops (n-PD) were significantly greater on the two resistant genotypes than on the susceptible genotypes (Fig. 1).

The mean durations per insect of pathway, xylem, and nonprobing phases (variables 8,9 , and 10; Tables

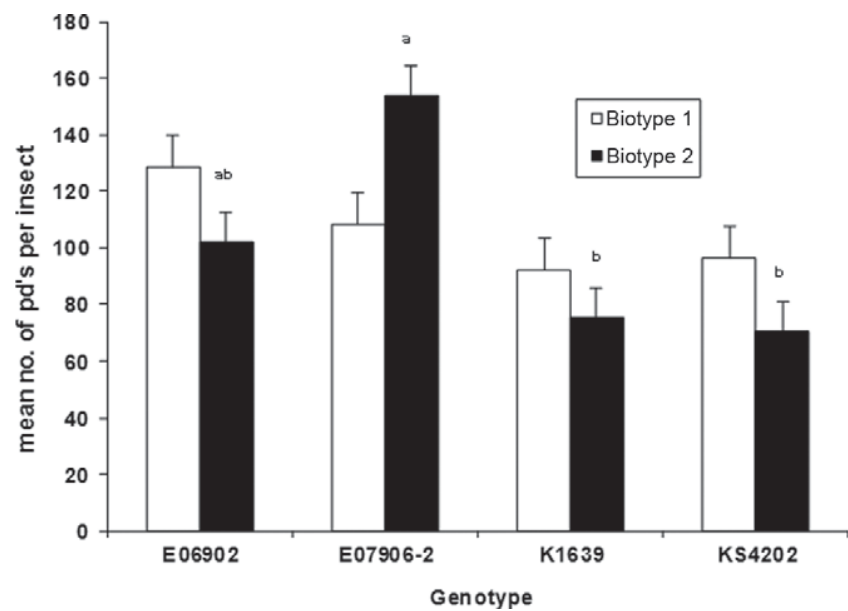

Fig. 1. Comparison of mean number of potential drops (n-PD) by aphid biotypes on resistant and susceptible genotypes. Bars followed by different letters are significantly different within each biotype $(P<0.05$; Tukey's test $)$. 


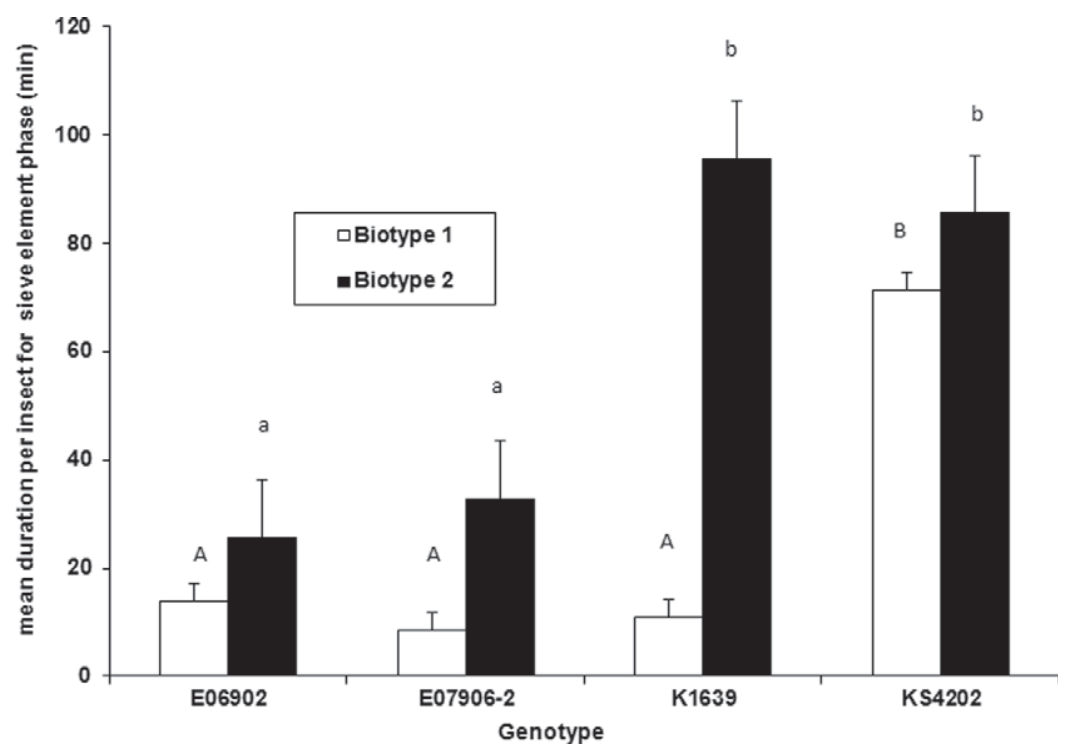

Fig. 2. Comparison of mean duration by aphid biotypes in SEP on resistant and susceptible genotypes for a 9-h (540-min) period. Bars followed by different letters are significantly different within each biotype $(P<0.05$; Tukey's test $)$.

1 and 2) were not significantly different $(P<0.05)$ between susceptible and resistant genotypes for either biotype. However, the mean duration per insect of sieve element phase (SEP) (Fig. 2) and the percentage time aphids spent in the sieve elements after the first sieve element phase (Table 1 and 2 ) were significantly $(P<0.05)$ greater on susceptible genotypes than on resistant ones, for both biotypes. Comparing the two aphid biotypes, biotype 2 produced longer duration of sieve element phases than biotype 1. Similarly, biotype 2 had a larger percentage time in sieve element phase after the first sieve element phase (variable 11) than biotype 1 on susceptible genotypes (Tables 1 and 2; Fig. 2). Finally, although no statistical test could be performed between experiments, out of 15 replications for each genotype, nearly all the aphids reached SEP on susceptible plants, whereas fewer than five aphids reached SEP phase in resistant genotypes, for both biotypes (Table 1 and 2).

\section{Discussion}

This EPG study reveals stylet probing in different tissues of resistant versus susceptible soybean plants. Comparing feeding behavior variables of soybean aphids on susceptible and resistant soybean genotypes demonstrates important factors related to resistance and susceptibility in soybean plants. The key waveform and key variable that summaries host plant resistance to aphid feeding is mean duration per insect of SEP (Han and Yan 1995). In this study, mean duration of SEP per insect was significantly different in susceptible and resistant genotypes with both biotypes. Out of the total time of recorded variables, mean SEP duration after the first probe to sieve elements in biotype 1 probing was $2-4 \%$ on resistant genotypes and up to $14 \%$ on susceptible genotype
KS4202. Likewise, in biotype 2 probing, mean SEP duration after the first probe to sieve elements was 4-6\% in resistant (E06902 and E07906-2) and 15-20\% in susceptible genotypes.

Shorter SEP duration in resistant genotypes shows that phloem tissues are the major source of tissue resistance (Han and Yan 1995, Prado and Tjallingii 2007). Here, K1639 showed resistance to biotype 1 with low SEP duration but susceptibility to biotype 2 with long SEP duration. This result agrees with the findings of Tjallingii (2006), which showed that plants resistant to one species or biotype of aphid may not be resistant to other species or biotypes, that is, resistance is specific to aphid type. Similarly, time from the beginning of recording to first SEP was significantly longer in resistant genotypes than in susceptible genotypes with both aphid biotypes. Annan et al. (2000) concluded that the factors for aphid resistance are located in or at least associated with phloem tissues and thus delay or eliminate access of aphid stylets to phloem tissues. In resistant genotypes, morphological or chemical factors may cause delay in the penetration of aphid stylets into sieve elements or may negatively change the feeding behavior of aphids because of antixenosis (Diaz-Montano et al. 2007). In this study, fewer than five aphids reached sieve element in resistant genotypes, but almost all aphids reached sieve element in susceptible genotypes.

As we discussed earlier, phloem phase plays a significant role in plant resistance to aphid feeding. The difference in the mean duration and percentage of SEP for the resistant versus susceptible genotypes was the best evidence for the presence of resistance factors in soybean genotypes. For phloem sap ingestion to succeed, aphids require the ability to overcome plant properties and defensive reactions associated with phloem (Tjallingii 2006). Phloem wound re- 
sponses are influenced by some proteins in sieve elements and are $\mathrm{Ca}^{2+}$ triggered (Knoblauch and van Bel 1998, Knoblauch et al. 2001). Molecular interactions between salivary proteins and calcium help the aphids obtain a continuous supply of phloem sap (detected via EPG) without occluding the sieve elements during their feeding (Will et al. 2007).

In this study, we also found that resistant genotypes took a longer time to reach the xylem phase than the susceptible genotypes, which may be because of either morphological or chemical factors in the resistant genotypes that affect the initial penetration of the aphid stylet into xylem and phloem tissues (Diaz-Montano et al. 2007). Changes in feeding behavior were mainly caused by the presence of antixenosis in resistant genotypes (Diaz-Montano et al. 2007).

Variable 7, the mean number of potential drops, was numerically greater on resistant genotypes with biotype 1 ; however, the difference was not significant. In contrast, the number of potential drops was significantly greater for resistant genotypes than susceptible genotypes with biotype 2 . These potential drops are brief $(5-10 \mathrm{~s})$ intracellular punctures by the stylets along their pathway and are also found in most sieve element tissues without going to phloem phase (Tjallingii and Hogen Esch 1993). During this process, aphids inject some watery saliva into the puncturing cells and collect some sap samples with their stylets (Martin et al. 1997). These samples may contain different chemical signals for continuous stylet penetration to plant tissues, and thus host plant acceptance by the aphids (Montllor and Tjallingii 1989). In wheat lines, although many repeated stylet penetrations (attempts) occurred into sieve elements preceding E1 (notably during late pathway pd's, also known as $\mathrm{X}$ waves), aphids failed to start E2 in resistant genotypes (Caillaud et al. 1995). Consequently, the greater number of potential drops observed in resistant genotypes, the greater difficulty of reaching the phloem phases, and thus leading to aphid rejection of the host plant.

Diaz-Montano et al. (2007) reported that both antibiosis and antixenosis were the categories of resistance present in sieve elements of resistant genotypes because they affected both the physiology and behavior of aphids, respectively. However, it was difficult to say which could be expressed more in most resistant genotypes. The presence of one category of resistance may be significantly affected by the other and thus, the behavior of aphids to probe into the sieve elements tissues (Diaz-Montano et al. 2007). In conclusion, the factors of resistance could be mainly related to sieve element phase and the aphid feeding behavior may be affected during the probing, especially in phloem tissues. EPG results demonstrated herein justify future studies of the chemistry of plant saps, principally phloem sap. Molecular and biochemical aspects of insect-plant interactions would provide additional insight into the plant resistance mechanism to aphids.

\section{Acknowledgments}

We thank Yoonseong Park and Jeremy Marshall for scientific advice; Elaine A. Backus for editorial comments and overall review; J. Robert Whitworth and Sruthi Narayanan for helpful suggestions; and The North Central Soybean Research Program and The Kansas Agricultural Experiment Station for funding.

\section{References Cited}

Annan, I. B., W. M. Tingey, G. A. Schaefers, W. F. Tjallingii, E. A. Backus, and K. N. Saxena. 2000. Stylet penetration activities by Aphis craccivora (Homoptera: Aphididae) on plants and excised plant parts of resistant and susceptible cultivars of cowpea (Leguminosae). Ann. Entomol. Soc. Am. 93: 133-140.

Caillaud, C. M., J. S. Pierre, B. Chaubet, and J. P. Di Pietro. 1995. Analysis of wheat resistance to the cereal aphid Sitobion avenae using electrical penetration graphs and flow charts combined with correspondence analysis. Entomol. Exp. Appl. 75: 9-18.

Clark, A. J., and K. L. Perry. 2002. Transmissibility of field isolates of soybean viruses by Aphis glycines. Plant Dis. 86: 1219-1222.

Crompton, D. S., and P. J. Ode. 2010. Feeding behavior analysis of soybean aphid (Hemiptera:Aphididae) on resistant soybean 'Dowling.' J. Econ. Entomol. 103: $648-$ 653.

Diaz-Montano, J., J. C. Reese, J. Louis, L. R. Campbell, and W. T. Schapaugh. 2007. Feeding behavior by the soybean aphid (Hemiptera: Aphididae) on resistant and susceptible soybean genotypes. J. Econ Entomol. 100: 984989 .

Ellsbury, M. M., E. A. Backus, and D. L. Ullman. 1994. History, development, and applications of AC electronic monitoring system for insect feeding, 128p. In Proceedings, Thomas Say Publications in Entomology. Entomological Society of America, Lanham, MD.

Han, X. L., and F. S. Yan. 1995. Stylet penetration behavior of the soybean aphid, Aphis glycines, on host and non-host plants. Acta Entomol. Sin. 38: 278-283. (http://www. k-state.edu/issa/aphids/reporthtml/trans104.htm).

Hill, C. B., L. Crull, T. K. Herman, D. J. Voegtlin, and G. L. Hartman. 2010. A new soybean aphid (Hemiptera: Aphididae) biotype identified. J. Econ. Entomol. 103: 509-515.

Hill, C. B., K. S. Kim, L. Crull, B. W. Diers, and G. L. Hartman. 2009. Inheritance of resistance to the soybean aphid in soybean PI 200538. Crop Sci. 49: 1193-1200.

Hill, C. B., Y. Li, and G. L. Hartman. 2006a. A single dominant gene for resistance to the soybean aphid in the soybean cultivar Dowling. Crop Sci. 46: 1601-1605.

Hill, C. B., Y. Li, and G. L. Hartman. 2006b. Soybean aphid resistance in soybean Jackson is controlled by a single dominant gene. Crop Sci. 46: 1606-1608.

Kim, C., G. Schaible, L. Garrett, R. Lubowski, and D. Lee. 2008a. Economic impacts of the US soybean aphid infestation: a multi-regional competitive dynamic analysis. Agric. Res. Econ. Rev. 37: 227-242.

Kim, K. S., C. B. Hill, G. L. Hartman, M.A.R. Mian, and B. W. Diers. 2008b. Discovery of soybean aphid biotypes. Crop Sci. 48: 923-928.

Knoblauch, M., and A.J.E. van Bel. 1998. Sieve tubes in action. Plant Cell 10: 35-50.

Knoblauch, M., W. S. Peters, K. Ehlers, and A.J.E. van Bel. 2001. Reversible calcium-regulated stopcocks in legume sieve tubes. Plant Cell 13: 1221-1230. 
Martin, B., J. L. Collar, W. F. Tjallingii, and A. Fereres. 1997. Intracellular ingestion and salivation by aphids may cause the acquisition and inoculation of non-persistently transmitted plant viruses. J. Gen. Virol. 78: 2701-2705.

McLean, D. L., and R. B. Kinsey. 1964. A technique for electronically recording aphid feeding and salivation. Nature 202: 1358-1359.

Montllor, C. M., and W. F. Tjallingii. 1989. Stylet penetration by two aphid species on susceptible and resistance lettuce. Entomol. Exp. Appl. 52: 103-111.

Ostlie, K. 2002. Managing soybean aphid. University of Minnesota, St. Paul, MN. (http://www.soybeans.umn.edu/ crop/insects/aphid/aphid_publication_managingsba. $\mathrm{htm})$.

Prado, E., and W. F. Tjallingii. 1997. Effects of previous plant infestation on sieve element acceptance by two aphids. Entomol. Exp. Appl. 82: 189-200.

Prado. E., and W. F. Tjallingii. 2007. Behavioral evidence for local reduction of aphid-induced resistance. J. Insect Sci. 7:48. (http://www.insectscience.Org/7.48).

Ragsdale, D. W., B. P. McCornack, R. C. Venette, B. D. Potter, I. V. Macrae, E. W. Hodgson, M. E. O'Neal, K. D. Johnson, R. J. O’Neil, and C. D. DiFonzo. 2007. Economic threshold for soybean aphid (Hemiptera: Aphididae). J. Econ. Entomol. 100: 1258-1267.

Ragsdale, D. W., D. J. Voegtlin, and R. J. O’Neil. 2004. Soybean aphid biology in North America. Ann. Entomol. Soc. Am. 97: 204-208.

Reese, J. C., W. F. Tjallingii, M. van Helden, and E. Prado. 2000. Waveforms comparisons among AC and DC electronic monitoring systems for aphid (Homoptera: Aphididae) feeding behavior, pp. 70-101. In G. P. Walker and E. A. Backus (eds.), Principles and Applications of Electronic Monitoring and Other Techniques in the Study of Homopteran Feeding Behavior. Thomas Say Publications in Entomology, Entomological Society of America Lanham, MD.

Sarria, E., M. Cid, E. Garzo, and A. Fereres. 2009. Excel workbook for automatic parameter calculation of EPG data. Comput. Electron. Agric. 67: 35-42.

SAS Institute. 2006. SAS/STAT user's guide, version 9.2. SAS institute, Cary, NC.

Tjallingii, W. F. 1988. Electrical recording of stylet penetration activities, pp. 95-108. In A. K. Minks and P. Harrewijn (eds.), Aphids: Their Biology, Natural Enemies and Control. World Crop Pests, Volume 2B. Elsevier, Amsterdam, The Netherlands.

Tjallingii, W. F. 2006. Salivary secretions by aphids interacting with proteins of phloem wound responses. J. Exp. Bot. 57: 739-745.

Tjallingii, W. F., and T. Hogen Esch. 1993. Fine structure of aphid stylet routes in plant tissues in correlation with EPG signals. Physiol. Entomol. 18: 317-328.

Venette, R. C., and D. W. Ragsdale. 2004. Assessing the invasion by soybean aphid (Homoptera:Aphididae): where will it end? Ann. Entomol. Soc. Am. 97: 219-226.

Walker, G. P., and E. A. Backus. 2000. Principles and Applications of Electronic Monitoring and Other Techniques in the Study of Homopteran Feeding Behavior. Entomological Society of America, Lanham, MD.

Wang, S., X. Bao, Y. Sun, R. Chen, B. Zhai, S. Y. Wang, X. Z. Bao, Y. J. Sun, R. L. Chen, and B. P. Zhai. 1996. Study on the effects of the population dynamics of soybean aphid (Aphis glycines) on both growth and yield of soybean. Soybean Sci. 15: 243-247.

Will, T., W. F. Tjallingii., A. Thonnessen., and A.J.E. Van Bel. 2007. Molecular sabotage of plant defense by aphid saliva. Proc. Natl. Acad. Sci. USA 104: 10536-10541.

Received 13 March 2013; accepted 27 June 2013. 